\title{
TECNOPOPULISMO O LA LÓGICA POLÍTICA DEL ACELERACIONISMO DE «IZQUIERDAS»: ENTRE AUTONOMÍA Y EQUIVALENCIA
}

\author{
Tecnopopulism or «Left» Accelerationism's Political Logic: between Autonomy \\ and Equivalence \\ Víctor Hermoso de Mendoza Pi \\ Universitat de Barcelona \\ victorhermosopi93@gmail.com
}

\begin{abstract}
Resumen:
Este artículo se propone abordar el aceleracionismo de Alex Williams y Nick Srnicek centrándose en su práctica emancipadora de producción de sujetos políticos. Si bien ha sido considerado como una "herejía marxista», lo cierto es que recoge la herencia del postobrerismo italiano, pero declinado en la lógica hegemónica del posmarxismo de Ernesto Laclau y Chantal Mouffe. Sin embargo, postobrerismo y posmarxismo comparten ciertos distanciamientos del marxismo «ortodoxo» en la formación de subjetividades políticas, pero una lógica emancipadora en conflicto. Así, el aceleracionismo de Srnicek y Williams se encuadra en esta disputa entre la experiencia autónoma de la «multitud» y la articulación equivalencial del «pueblo», y nuestro objetivo será problematizar esta hibridación en vías de reconceptualizar este aceleracionismo como un tecnopopulismo.
\end{abstract}

\section{Palabras clave:}

aceleracionismo, posmarxismo, postobrerismo, multitud, pueblo, tecnopopulismo

\begin{abstract}
:
This paper aims to present the contemporary accelerationism of Alex Williams and Nick Srnicek focusing on their take on the emancipating production of political subjects. Even though their views have been understood as a Marxist heresy, it turns out they behold the legacy of PostWorkerism (also known as the Italian theory or Autonomism) which they actually sketch out as a declension of the hegemonic logic of the PostMarxism of Ernesto Laclau and Chantal Mouffe. As a matter of fact, PostWorkerism and Post-Marxism both diverge from conventional Marxism and its understanding of the rise of the political subject - yet follow two different logics of emancipation. In this article, Srnicek and Williams's accelerationism is situated in the frame of a dispute between two confronted theoretical currents: the autonomous experience of the
\end{abstract}


multitude, and, the equivalential articulation of «the people». The discussion of this hybridization leads me to the reconceptualization of their accelerationism as a tecnopopulism.

\section{Keywords:}

Accelerationism, Post-Marxism, Post-Workerism, Multitude, People, Tecnopopulism

Recibido: $27 / 03 / 2020$

Aceptado: $17 / 10 / 2020$

\section{Introducción}

La reciente refundación del movimiento aceleracionista por parte de Nick Srnicek y Alex Williams a partir de la publicación del Manifiesto por una Política Aceleracionista (2013), así como su continuación y expansión en Inventing the future (2015), constituye una interesante renovación de una programática izquierdista para afrontar los retos sociopolíticos contemporáneos. El aceleracionismo es una corriente filosófica estética y política que hunde sus raíces en la teoría de la desterritorialización y reterritorialización de Gilles Deleuze y Felix Guattari de los años setenta, la cual ya en los años noventa es recogida por Nick Land, el director de la Unidad de Investigación de la Cultura Cibernética (CCRU por sus siglas en inglés) y el así reconocido como padre del aceleracionismo contemporáneo (Noys, 2018). De manera genérica el aceleracionismo apuntaría a «identificar, profundizar y radicalizar las fuerzas de la desterritorialización con el objetivo de superar las tendencias compensatorias que suprimen la posibilidad de una transformación social de gran alcance» (Wolfendale, 2014). Así, los diversos aceleracionismos, tanto los mecanicistas como los navegacionales, ${ }^{1}$ comparten la asunción de que la intensificación de ciertas tendencias

\footnotetext{
${ }^{1}$ Evidentemente, cuando se habla de aceleracionismos se alude de manera genérica a toda una amalgama de corrientes que se adscriben de una manera u otra a ciertos principios básicos esenciales. Entre todos ellos hay diferencias fundamentales que merecerían ser sistematizadas $y$, aunque este no es el objetivo de este ensayo, si debiese destacarse la ambigüedad y arbitrariedad ideológica ( $y$ a menudo poco fundamentada) con la que se han establecido unas categorizaciones que apenas han encontrado réplica. Así, generalmente se alude a una aceleracionismo de «izquierdas» y a otro de «derechas». En este artículo me ocuparé principalmente de una de las vertientes «izquierdistas» del aceleracionismo, la de Srnicek y Williams. Aclarada esta cuestión me gustaría añadir a modo de prescripción que una sistematización más adecuada sería tomar el aceleracionismo por un criterio sustancialista, uno que refiero a la naturaleza de su aceleración y no por un criterio consecuencialista del mismo, es decir, por los resultados que se esperan con dicha aceleración ya sean estos progresistas o reaccionarios. Mi propuesta consiste en distinguir entre: aceleracionismos mecanicistas, aquellos que se funden con el mero despliegue del capital y buscan aplicarle velocidad esperando así el colapso, y navegacionales, aquellos que pretenden acelerar o explorar ciertas tendencias del capital que puedan dirigirlas hacia fines sociales. A pesar de ser una categorización preliminar y que debe ser sometida a debate, creo que ofrece herramientas más
} 
del desarrollo tecnológico-capitalista conduciría al colapso del sistema o hacia un afuera del mismo, es decir, al advenimiento del postcapitalismo: un mundo más allá de los resortes de la lógica de la búsqueda de beneficio extractivista y de la escasez generalizada. De la misma manera que Marx afirmó que las revoluciones son la "locomotora de la historia», por analogía los aceleracionismos aseveran que no debemos sino acelerar el tren de la historia.

De la adscripción del aceleracionismo a un cierto tipo de determinismo tecnológico que entendería que la tecnología puede modificar, suscitar o guiar los cambios históricos, económicos o sociales, en confrontación a otras acepciones constructivistas, ${ }^{2}$ no vamos a pronunciarnos en este artículo. El objetivo de este es el de analizar su lógica política y su potencialidad de creación de sujetos emancipadores. Tanto es así que en el seno del aceleracionismo de Srnicek y Williams convergen dos lógicas de la producción de agentes sociales que a priori parecen inconmensurables. No en vano, el aparente interés de ambos autores ha sido compatibilizar dos tradiciones filosóficas emancipatorias: el posmarxismo de Ernesto Laclau y Chantal Mouffe, y el postobrerismo de autores (ya de por sí dispares) como Antonio Negri, Franco Berardi 'Bifo', Paolo Virno, etc.

Tanto postobrerismo como posmarxismo comparten el interés en dar respuesta a la creciente dificultad histórica de la tradición marxista de constituir una unidad de clase ${ }^{3}$ frente a una cada vez mayor heterogeneidad empírica de lo social en el capitalismo avanzado. Dada esta imposibilidad ontológica (no práctica), contemplan la formación de esta unidad intentando deshacerse de los fundamentos esencialistas del marxismo clásico, aunque como desarrollaremos, esta es articulada desde lógicas divergentes. Por un lado, encontramos en el postobrerismo, una lógica de la autonomía de los diversos agentes sociales. Por el otro lado, en el posmarxismo, una lógica de equivalencia entre diferentes posiciones objetivas de lo social. Esta es la disputa entre la conformación inmanente de una multitud y la articulación de un pueblo desde una trascendencia que en último término nunca es definitiva.

La conclusión a la que pretende llegar el artículo es que el aceleracionismo de Srnicek y Williams se aleja de una concepción autonomista de la política y, en cambio, toma la forma de un posmarxismo, aunque sin deprenderse del todo de ciertos aportes de la teoría autonomista. Es por esta razón que se ha decidido denominarlo como un tecnopopulismo. Así, en un primer término nos ocuparemos de trazar un primer

adecuadas para atrapar la complejidad y diversidad de estas corrientes. Una sistematización que dejaremos para otros análisis posteriores.

${ }^{2}$ En relación con la nota anterior, podríamos afirmar que los aceleracionismos mecanicistas suelen participar de un tipo de determinismo que considera a la tecnología un agente con autonomía diferenciada de los contextos humanos, mientras que los aceleracionismos navegacionales necesariamente deben incluir una comprensión constructivista del desarrollo tecnológico.

${ }^{3}$ Tanto en el postobrerismo como en el posmarxismo no nos referimos a un «Uno» que anule y subsuma la heterogeneidad, se trata más bien de buscar una regularidad en la dispersión, la equivalencia en la diferencia. 
esbozo del concepto de tecnopopulismo mientras analizamos las concepciones confrontadas que se hayan en su seno: el pueblo laclauiano y la multitud negriana, para después referirnos a las lógicas políticas que las dinamizan y su posible complementariedad en el seno del aceleracionismo de Srnicek y Williams. La noción de universalidad de los autores británicos nos llevará a concluir que, aunque tomen elementos y herramientas de análisis del postobrerismo, su aceleracionismo se aleja de concepciones inmanentistas y mecanicistas de la política para acercarse a una matriz posmarxista: un populismo fundamentado sobre medios tecnológicos. Consecuentemente el objetivo del artículo será problematizar esta hibridación de tradiciones en el seno del aceleracionismo de Srnicek y Williams desentrañando su lógica propia y, así, justificar la idoneidad del término tecnopopulismo.

\section{1. ¿Qué es el tecnopopulismo?}

Existen ciertamente motivos por los que renombrar el aceleracionismo de Srnicek y Williams. Primeramente, es un término equívoco que tiende a confundirlo con el aceleracionismo de Nick Land, el padre de su fundamentación más reciente. El propio Srnicek reconoció en una entrevista reciente que el nombre era ya inservible, (Gureev, 2018) y así lo demostró en Inventing the future (2015), continuación del Manifiesto por una Política Aceleracionista (2013) (MPA en adelante), en el que se usa una sola vez el término "aceleración». En segundo lugar, nuestra propuesta de denominarlo como un tecnopopulismo responde a la exigencia de aclarar las herencias filosóficas del movimiento, afirmando al mismo tiempo sus aportaciones, así como desligarlo de un aceleracionismo izquierdista de tipo mecanicista. En este sentido, el tecnopopulismo tendría una filiación posmarxista que en ocasiones ha sido ignorada.

Ciertamente, los análisis habituales sobre el aceleracionismo ${ }^{4}$ de Srnicek y Williams han insistido en su conexión con el postobrerismo dado que ambos parecen partir de una cierta lectura del famoso Fragmento sobre las máquinas (1972) de Karl Marx. Tanto es así que el propio Antonio Negri reconoció ver en el MPA un «complemento postobrerista» (Negri, 2017: 84) ya que en este primer texto de Srnicek y Williams se analizaban las tendencias del desarrollo capitalista para su apropiación y redirección, es decir, la propuesta inmanentista de profundizar en ciertas líneas de despliegue del capital que lo puedan llevar a un afuera, al postcapitalismo. El inmanentismo de base en Srnicek y Williams, que Negri se afana en descubrir, consiste en afirmar que hay una tendencia o fuerza inmanente en el socius capitalista cuyo desarrollo puede superar su propia morfología, siendo esta potencialidad sistemáticamente castrada por su misma composición técnica.

En la intensificación o profundización de esta tendencia que deviene virtualidad, encontramos el proyecto del «fin del trabajo» de Srnicek y Williams. Esta es, sin duda, una herencia de la consigna del «rechazo del trabajo» postobrerista. Sin embargo, esta reclamación que hizo eco en la larga «década del 68»(Badiou, 2010: 52) ha sido

\footnotetext{
${ }^{4}$ Véase el artículo de ARROYO GARCÍA, Nantu y ACOSTA IGLESIAS, Lorena (2019). "Pensar el aceleracionismo, ¿con o contra Marx? El fragmento sobre las máquinas a debate en el s. XXI". Argumentos de Razón Técnica, 22, pp. 178-20.
} 
resignificada a un presente de precariedad generalizada, en el que el trabajo no puede asegurar el mantenimiento vital: lamentablemente en nuestro presente ya no es posible afirmar que "ser precario es lindo» ${ }^{5}$ (Gómez Villar, 2014: 72). En la contemporaneidad, la resignificación del «rechazo del trabajo» obrerista por el horizonte postrabajo del aceleracionismo de Srnicek y Williams surge tras la posibilidad de la automatización tecnológica de los procesos productivos. Para los autores británicos, esta tendencia del desarrollo productivo podría desligar la relación salario-trabajo (Srnicek; Williams, 2015: 109-114) y el establecimiento de una renta básica universal, un objetivo típicamente postobrerista. Consecuentemente, el esquema postobrerista es similar: el quehacer biopolítico de la multitud sería capaz de liberarse de la captura capitalista y fundar nuevas formas institucionales, organizaciones de vida en común al margen del capital, es decir, liberar la relaciónsalario trabajo desde la propia inmanencia del sujeto. Esta posibilidad reside en el tránsito histórico del fordismo al postfordismo en el que el valor ha perdido toda medida de cuantificación una vez este es extraído de la comunicación o los afectos (Hardt; Negri, 2004: 136-137). Así, el postobrerismo anticipa la tendencia del sujeto a devenir in-valorizable y escapar de la captura del capital. Línea de despliegue que, como vemos, Srnicek y Williams retoman y resignifican en nuestro presente postfordista.

Pese a esta clara imbricación entre el postobrerismo y el aceleracionismo de Srnicek y Williams que incluso ha llevado a Franco Berardi 'Bifo' a ver en el MPA una expresión radical del inmanentismo comunista (2017: 75), encontramos que el proyecto de Srnicek y Williams es, sin embargo, conceptualizado en Inventing the future (2015) como una práctica concentrada en la formación hegemónica de un pueblo articulado en torno a un «nuevo sentido común»: una sociedad postrabajo (Srnicek; Williams, 2015: 132). En estos términos, se entendería que las vías de profundización en las líneas postrabajo no son delegadas a un simple determinismo o mecanicismo, es decir, no se funde con el mero movimiento del capital esperando que (Dios mediante) acabe por autodestruirse, tampoco a la libre acción espontánea del «estar en contra» de la multitud (Hardt; Negri, 2002: 199). Al contrario, en este aceleracionismo (que podemos Ilamar populista en cuanto busca la formación de hegemonías, y tecnopopulista, dado que cimienta esta hegemonía en la profundización en estructuras y medios tecnológicos) existe un pueblo que ha hegemonizado ciertos significantes flotantes dentro de un marco discursivo para crear un consenso en torno al redirigimiento o navegación del curso de la economía y la tecnología hacia fines sociales, es decir, en dirección al postcapitalismo. Desde esta perspectiva, la ruptura de la relación salario-trabajo sería alcanzada políticamente, no espontáneamente. En vista a esta nueva formulación navegacional del aceleracionismo, podríamos afirmar que, siguiendo la analogía establecida por Marx, no se trata de acelerar el tren de la historia, sino de «hacerlo saltar de las vías», como diría Walter Benjamin, y redirigirlo.

\footnotetext{
${ }^{5}$ La flexibilidad fue precisamente una de las reivindicaciones de las protestas italianas del 77. Entonces se entendía como una liberación frente a la vida repetitiva y embrutecedora del fordismo.
} 
Consecuentemente, el término que proponemos, tecnopopulismo, busca aunar estas dos herencias: al fin y al cabo, la persecución de un movimiento populista en las líneas de despliegue de la posibilidad del fin del trabajo no es sino una declinación del populismo en clave tecnológica. En este sentido, Srnicek y Williams entienden que el concepto de hegemonía de Laclau y Mouffe es insuficiente para afrontar los retos contemporáneos (creciente desempleo, desigualdad, masas de población excedentes de la producción, así como la amenaza de la automatización) por lo que debe proponerse una hegemonía tecnosocial (2015: 136) o una complex hegemony (Williams, 2020) en la que la hegemonía discursiva es complementada con una teoría de la complejidad en la que la presta atención colateralmente a los medios materiales, logísticos e infraestructurales que puedan dirigirnos hacia el postcapitalismo. En cierta medida atienden al hecho de que hoy en día nuestro mundo esta tecnológicamente construido, y que cualquier intento de superar el capitalismo debe poner los medios tecnológicos e infraestructurales para tal empresa.

\begin{abstract}
If complexity ${ }^{6}$ presently outstrips humanity's capacities to think and control, there are two options: one is to reduce complexity down to a human scale; the other is to expand humanity's capacities. We endorse the latter position. Any postcapitalist project will necessarily require the creation of new cognitive maps, political narratives, technological interfaces, economic models, and mechanisms of collective control to be able to marshal complex phenomena for the betterment of humanity (Srnicek; Williams, 2015: 16).
\end{abstract}

Esto no significa que ya no se le de relevancia al discurso en la creación y apelación de subjetividades, más bien al contrario, en el caso de Srnicek y Williams se trataría de atender tanto lo discursivo como lo material, haciendo hincapié en que lo primero debe ser fundamentalmente sustentado en lo segundo. Esto no debe hacernos confundir la teoría posmarxista como una teoría del discurso meramente idealista. Como el autor afirma, su teoría del discurso es materialista (Laclau; Mouffe, 2015: 146147). Srnicek y Williams retomarían una teoría materialista del discurso a la que añadirían los recursos materiales que pueden hacer viables un concepto de hegemonía extradiscursiva. En este sentido, Alex Williams acusa a la teoría hegemónica laclauiana-mouffiana de conformarse con las prácticas discursivas y, por consiguiente, relegarla al ámbito meramente ideológico. Como contrapunto Williams vuelve a los análisis de la hegemonía gramsciana y recompone la noción de hegemonía en colaboración con las teorías de la complejidad, surgiendo de tal proyecto una teoría realista de la hegemonía en la que economía y política no se vean atravesadas por un vector unidireccional de determinismo causal, sino que son comprendidas como esferas en retroalimentación y en recomposición constante. De esta manera, deja atrás el esencialismo gramsciano que ya habían criticado Laclau y Mouffe, pero sin perder

\footnotetext{
${ }^{6}$ Recientemente Alex Williams ha publicado un libro en el que expone la complementariedad entre las teorías de la complejidad y los análisis de hegemonía política, así como la necesidad de su mutua imbricación. Véase: WILLIAMS, Alex. (2020). Political hegemony and social complexity. Mechanisms of power after Gramsci. Londres: Palgrave Macmillan.
} 
el carácter complejo y multidisciplinar de la teoría gramsciana de hegemonía (Williams, 2020: 88):

Yet the shift towards a social ontology of discourse, operating on languagelike relations of difference and equivalence becomes increasingly incoherent the further the object of analysis moves from ideology towards the material, the scientific, the technological, or the infrastructural. As such, we ultimately conclude that the discursive turn in hegemony theory is one which failed to preserve the full complexity of the social (Ibid., 8-9).

Esta hegemonía realista enlaza con la búsqueda de dotar su teoría política un cierto arsenal de conceptos republicanos. Consecuentemente, frente a la libertad negativa propia del liberalismo formulan una concepción de libertad sintética (Srnicek; Williams, 2016: 78-83) (término que sería equivalente a la libertad positiva republicana) por la que entienden que una libertad que no cuente con los medios materiales para su realización pierde efectivamente tal estatuto. En la misma línea, en su conceptualización de progreso no existe una fe o esperanza ciega tal y como fue teleología kantiana: una fuerza trascendente en forma de razón que acompaña la humanidad por la historia en el camino a su plenitud, sino que se reconoce que el progreso no es factor necesario en el despliegue de la historia humana, más bien se trataría de una posibilidad que debe ser alcanzada materialmente. Esta posibilidad de progreso es además entendida por Srnicek y Williams como una ficción hipersticional (2016: 71-75). Esto es una ficción autocumplida, un relato anticipatorio que en el momento que se despliega genera unos afectos y deseos que catalizan su futuro cumplimiento. Una profecía que, al estilo kantiano (paradójicamente), ayuda a cumplir aquello que profetiza o, en otros términos, un mito, tal y como Georges Sorel entendió el marxismo (Laclau; Mouffe, 2015: 73).

Consecuentemente, podríamos conceptualizar el tecnopopulismo como un intento de rellenar el "vacío» programático de Laclau y Mouffe, con reivindicaciones típicamente postobreristas como son: la apropiación de los medios de producción, la renta básica universal o el derecho cosmopolita. ${ }^{7}$ De la misma manera, esta imbricación parece seguir, como antes señalábamos, el intento de Mouffe de «salvar la democracia» y constituir una democracia radical y plural (Mouffe, 1999: 21-25). ${ }^{8}$

Ahora cabe preguntarse si esta complementariedad o hibridación entre postobrerismo y posmarxismo es acertada o puede tener una declinación política

\footnotetext{
${ }^{7}$ Estas son precisamente las tres demandas que Negri y Hardt proponen para su programa político. Véase: Imperio (2002), pp.362-368.

${ }^{8}$ Para Srnicek y Williams el proyecto de Mouffe sería en vano si las condiciones materiales que sustentan una democracia no están aseguradas. En las actuales condiciones en las que cada vez más ciudadanos devienen excedentes respecto a la producción (y, por tanto, pierden su condición de ciudadanos) se correría el riesgo de mantener una definición procesual y no sustancial de la democracia (Srnicek; Williams, 2017: 44). Efectivamente, el proyecto de Srnicek y Williams encajaría en una matriz republicana que, si bien algunos autores como José Luis Villacañas (2015) han tratado de oponer a la tradición populista, esta es perfectamente compatible con el posmarxismo, como muestran los esfuerzos teóricos de Chantal Mouffe (1999) o la propia experiencia populista en España, como ha recalcado Fernández Liria (2016).
} 
coherente en la conformación de subjetividades políticas y proyectos transformadores. Esto supone preguntarse hasta qué punto la lógica equivalencial en Laclau es complementaria con la propuesta de autonomía de Negri, o cómo es posible compatibilizar la inmanencia de despliegue de las tendencias con una forma de representación de «intereses» o una trascendencia (fallida). Como más arriba comentamos, pese a que el objetivo tanto del posmarxismo como del postobrerismo sea el de constituir una mayoría social, un contrapoder, lo cierto es que en un primer término, las lógicas de conformación y articulación de estas difieren ontológicamente.

\section{Entre multitud y pueblo}

Para Laclau y Mouffe (2015: 45) la "crisis del marxismo» en el seno de la $2^{\circ}$ y $3^{\circ}$ Internacional se refiere a un momento en el que la predicción de la tendencia económica y social no se corresponde al desarrollo de las fuerzas productivas «reales» $y$, consecuentemente, el marxismo se queda huérfano de herramientas conceptuales para explicar la lucha de clases. Marx había condicionado la unidad de clase a un desarrollo capitalista que tendía a pauperizar crecientemente a la población y a la convergencia en el estatus de obrero de cada vez mayores segmentos sociales (Ibid., 44). Era esta tendencia homogeneizante la que permitía afirmar a Marx el carácter ontológicamente privilegiado de la clase obrera como sujeto universal en tanto que referente último o fundamento desde el que construir el comunismo: la clase obrera y sus intereses constituían la vanguardia de la historia. Sin embargo, la realidad sucesiva mostró todo lo contrario: un "desarrollo desigual y combinado" entre los países capitalistas, así como una tendencia a la diversificación y multiplicación de intereses en el seno de la propia clase. En este contexto, el marxismo ortodoxo tuvo que llenar su relato historicista y economicista de «excepciones» históricas (contingencias cuyo desarrollo histórico serían reconducidas en último término), así como apelar a la concepción idealista de una «falsa conciencia» que alejaba a los obreros de los intereses que realmente los representaban (Ibid., 109-110).

Desde esta perspectiva, podríamos considerar que tanto el postobrerismo como el posmarxismo son intentos de racionalizar experiencias políticas (Pizzi, 2018: 59) que habían excedido el marco teórico en el que el marxismo ortodoxo había pensado la lucha de clases. Tanto los procesos latinoamericanos, así como «la década del 68» se presentan como experiencias políticas en las que la clase no es el centro irradiador o sujeto privilegiado de los movimientos de emancipación y cambio político. Consecuentemente, el esfuerzo de ambos es el de conceptualizar un nuevo marxismo en el que la clase obrera y la noción esencialista de sujeto quedan descentralizados.

Para el postobrerismo esto supone dejar de concebir a la clase obrera como anterior a su propia organización, como si fuese una categoría fija y determinable a priori por unos intereses compartidos. En realidad la clase obrera es el resultado de los ciclos de protesta; es, por tanto, resultado de una cierta composición social. A esta se le opone una composición técnica que intenta capturar la primera y, este proceso, denominado como ciclo de lucha, vuelve a comenzar. Mario Tronti afirmó: «primero las luchas, luego el desarrollo capitalista», mediante este giro copernicano busca dotar a los obreros de una actividad y capacidad creativa que hasta ahora se le había negado 
(Gómez Villar, 2014: 21). Para 'Bifo' esto supone que el obrero ya no es el sujeto pasivo de una explotación, sino que es activo en su propio devenir y prefigura las formas de desarrollo capitalistas, en cuanto que su capacidad creativa de exceder al capital obliga a este a producir nuevas formas de capturar su valor (2016: 17).

Abandonar la clase y la noción idealista de falsa conciencia, también comporta en el postobrerismo que ya no exista la alienación del obrero, sino un extrañamiento fruto de «la confrontación de la conciencia en la escena de su exterioridad» ante la dependencia del trabajo (Ibid., 17). En ese sentido se discute el ideal de unos intereses que definen y unifican a una clase obrera de manera trascendental: la capacidad de extrañamiento y de conformar una lucha es siempre el fruto de una composición de clase, ya no hay pues espacio para unas condiciones materiales, una economía o infraestructura que determine a priori los resultados de ciertas conformaciones políticas. Esta posible composición es siempre fruto de un carácter ontológico, y es que, como afirman Hardt y Negri, el ser humano tiene una natural predisposición a la resistencia y a rebelarse contra el poder, a "estar en contra»: hay una experiencia ontológica de la autonomía (2004: 228). Es aquí desde donde Hardt y Negri pueden construir una unidad en torno a una lógica inmanente en la posibilidad de que los agentes sociales devengan autónomos de las lógicas del capital: el desarrollo de su natura/ resistencia al poder, y la producción biopolítica de los sujetos devendría tan excedente con respecto a las formas de captura capitalista que este devendría invalorizable, así la multitud como pluralidad se organizaría y dejaría obsoleta la maquinaria extractivista capitalista. Este despliegue de la multitud, su natural tendencia a "estar en contra», sería entonces plenamente inmanentista. No requeriría de articulación política y, consecuentemente, rechazaría cualquier tipo de instancia de mediación representativa: partido, estado, etc. Evidentemente, el esfuerzo postobrerista es el de construir un marxismo sin teleología, ni historicismo, economicismo o dialéctica. O más bien, la construcción de, por un lado, una «dialéctica no negativa» (Negri, 2006: 48) que no contiene ni su superación ni la reintegración de la negación y, por otro lado, una teleología materialista (Hardt; Negri, 2002: 74).

El posmarxismo de Laclau y Mouffe igualmente reniega del esencialismo marxista, pero también de la centralidad del trabajador como sujeto privilegiado que el postobrerismo parece haber querido mantener. ${ }^{9}$ En cambio, ellos entienden que no hay intereses a priori ni sujetos privilegiados en torno a la posición que ocupan en las relaciones de producción a la hora de encarar la articulación de un proyecto político. En última instancia, lo social siempre representa un exceso de sentido que no puede ser fijado de manera definitiva, ya que las posiciones e intereses de los agentes sociales nunca están explicitadas del todo. Los intereses o posiciones de sujeto no son producto de un sujeto racional, tal y como pretende el liberalismo, ni tampoco predecibles de su lugar en las relaciones de producción, sino que surge de una conformación política que crea y sustenta dichos intereses. Esta falta de sentido último en lo social refiere a

\footnotetext{
${ }^{9}$ Evidentemente cuando Negri habla de trabajadores expande el campo de la producción a los afectos y a la comunicación, es decir, al trabajo cooperativo en el sustento y producción de una comunidad y, consecuentemente, pretende aunar bajo tal denominación a la sociedad en su conjunto.
} 
la misma imposibilidad de ser suturada o cerrada (Laclau; Mouffe, 2015: 112-123). Consecuentemente, desde un análisis economicista, no pueden extraerse los intereses de una "clase", ni mucho menos ser nombrada como tal. El nombre es siempre el resultado de un acto político-discursivo (Ibid., 150-151).

Con tal de que la pluralidad de lo social sea reconducida a una unidad (siempre contingente y sometida a su recomposición), Laclau construye su noción de pueblo en torno a una lógica de la equivalencia: lo político nunca esta prefigurado por formas sociales o económicas, sino que surge de establecer equivalencias en torno a demandas presentes en el ámbito social. De esta manera, la política no es una mera representación de intereses, sino la articulación de una serie de posiciones de sujeto que crea dichos intereses (Laclau, 2018: 200). Dado que del orden social no se puede extraer a priori las posiciones de un sujeto, la política se basará en articular en una cadena de equivalencias una serie de demandas, las cuales no tienen ninguna relación de necesidad entre ellas. La equivalencia no disuelve la especificidad de estas demandas (en ese caso hablaríamos de simple identidad entre demandas), sino que las totaliza parcialmente, las unifica respetando sus diferencias (Ibid., 104). Así, el pueblo o la hegemonía popular es el resultado de una articulación política en torno a una serie de demandas insatisfechas; en un primer momento, las demandas se sitúan en la institución, pero al ser rechazadas, estas finalmente devienen contra de la institución (Gómez Villar, 2018: 33-39). Al no ser satisfechas, estas demandas cristalizan en la formación de una identidad popular creando así un antagonismo en el seno de lo social. Sin embargo, este momento de redefinición de las identidades sólo es posible, en un momento de "crisis orgánica» (Laclau, 2018: 166), en las que identidades han debilitado su fijación a otras articulaciones discursivas. Finalmente, si para el posmarxismo desde lo social no se construye necesariamente lo político es impensable la auto-institución de unos intereses inmanentes, es por tanto necesario un acto de representación política que fije (parcialmente) unos intereses. Sin embargo, Laclau afirma que esta trascendencia o representación es fallida, es "la presencia de una ausencia» (Ibid., 303). Consecuentemente, es imposible fijar o suturar lo social por completo, siempre quedará sometido a rearticulaciones.

En base a las lógicas propuestas, los objetivos de ambos son distintos atendiendo a la propia naturaleza ontológica en la que ambos piensan lo político. Así, aunque en ambos casos la democracia es el objetivo último de estos movimientos, Laclau y Mouffe desean radicalizar el proyecto de democracia radical y plural, mediante una articulación hegemónicas de diferencias unificadas en torno a demandas, reivindicando así el carácter plural y heterogéneo de una sociedad, de la cual no puede eliminarse el antagonismo. Este es precisamente el límite de lo social. De hecho, para los autores no existiría una democracia como tal si no tuviera cabida el disenso (Ibid.). Mientras, el esfuerzo de Negri se centra en una nueva concepción de la democracia postmoderna (2016: 9): un cambio de sentido en el que la democracia se transforma, en términos rousseaunos, desde la voluntad de todos a la voluntad general, fruto de la organización y participación de las singularidades que pueblan la multitud, nunca en todo caso reducidas a una unidad (Ibid., 151-152). Observamos que postobrerismo y posmarxismo no solo divergen desde sus principios teóricos, sino que como fruto de las diferentes estrategias políticas y las lógicas internas que los dinamizan, el proyecto resultante debe ser $y$ es consecuentemente distinto. 
Recordemos, la disyuntiva en la que se encuentra el aceleracionismo contemporáneo o tecnopopulismo es la complementariedad entre la articulación de un pueblo en clave posmarxista: una concepción de hegemonía fruto de una lógica de la equivalencia, y la experiencia de la multitud propia del postobrerismo: de la formación de lo común a partir de una lógica inmanente de tendencia a la autonomía.

También podemos reconocer una cierta similitud en la constitución del sujeto emancipatorio en el posmarxismo y el postobrerismo. Ciertamente habría una cierta analogía entre el concepto de multitud de Negri y Hardt con el de pueblo de Laclau y Mouffe (Laclau, 2018: 299) dado que ambas categorías pretenden aunar en su seno la heterogeneidad de lo social sin neutralizar las diferencias. Así, si la multitud anula cualquier privilegio ontológico trascendental, sí que mantiene la fundamentación de un sujeto emancipatorio a priori. En el caso del posmarxismo, la noción de pueblo es una categoría vacía y es que no se sustenta en ningún principio inmanente al orden social, el resultado de lo que es el pueblo depende de su articulación política en un contexto determinado. Así, como reconoce Laclau, el vacío propio del populismo también puede encontrarse en la categoría de multitud, cuando los autores fundamentan un principio general y universal de "estar en contra», sin especificar como y contra qué, de la misma manera que pueblo puede referirse a la creación de proyectos populares de signo antagónico.

La diferencia entre multitud y pueblo estriba, tal y como ya hemos visto, en su propia concepción de la articulación política. En el postobrerismo de Negri, hay una tendencia convergente de la multitud a «estar en contra», a rebelarse contra el biopoder y escapar de la captura capitalista. De esta confrontación contra el Imperio las luchas convergerían en la conformación de instituciones públicas de autoorganización que acabarían por derrocar el Imperio, es decir, en la autonomía. Esto sería posible en cuanto que el sujeto del postfordismo, habría integrado en sí una serie de capacidades que son la fuente y creación de valorización en el capitalismo: creatividad, lenguaje, afecto... Esta tendencia a la autonomía, a desarrollarse lejos de la esfera del capital y la valorización es inmanente, se encuentra como conatus spinoziano en la misma naturaleza de la multitud. El problema de tal aseveración observa Laclau, es que la construcción de una voluntad general no puede ser construida espontáneamente si partimos de la heterogeneidad de lo social, al menos debería admitir un grado de articulación política (Laclau, 2016: 140). Así, Laclau dota de prioridad al acto de la articulación política, la unidad (el pueb/o) resultante de una heterogeneidad no reside en categorías inmanentes, sino en la producción de lógicas equivalenciales entre las diferentes posiciones de sujeto que ocupan lo social, es decir, desde una lógica trascendente.

\section{Entre equivalencia y autonomía}

Las lógicas de inmanencia (autonomía) y de trascendencia (equivalencia) difieren en cuanto que la primera implica el funcionamiento de un mecanismo universal (el «estar en contra») que requiere en última instancia de un actor histórico universal ya preconstituido (la multitud), mientras que la segunda evita cualquier atribución a una clase o sujeto el privilegio (ontológico, no práctico) por el que se erigirá un sujeto o 
identidad emancipadora. Esta diferencia resulta en última instancia de lo que cada una de las posiciones entiende por el concepto de universalidad y del lugar que este concepto ocupa en su esquema. En el inmanentismo de Hardt y Negri la universalidad se entiende como una categoría subyacente a cualquier individuo, es decir, establecen un principio universal presente en la totalidad de lo social como fundamento de lo político, lo que facilita así la reacción espontánea contra los límites del Imperio. De aquí podemos concluir que la universalidad debe referir en oposición o resistencia a algún mecanismo que opere de manera global: el capital, cuya eliminación, supondría consecuentemente el fin de la política y la eliminación de toda forma de trascendencia y/o representación. En el caso de Laclau, no se acepta una universalidad preconstituida y universalista, sino que el concepto de la universalidad es parcial, no tiene un contenido propio o identificable en lo social. Establecer lo contrario supondría erigir un fundamento en torno a un sujeto desde el cual pensar la política, atribución esencialista que Laclau y Mouffe tratan de sortear. Para el posmarxismo el universal se trata más bien de una parcialidad que se inviste de universalidad. Consecuentemente, la universalidad es una construcción política contingente y siempre revisable, es decir, es el resultado de una construcción hegemónica (Laclau, 2016: 125-140).

El problema que debemos afrontar ahora es si esta lógica de la inmanencia puede ser compatible o no con ciertas formas de trascendencia. En este sentido, Laclau afirma que la lógica de la autonomía10 no tiene por qué entrar en contradicción con una lógica equivalencial. Ciertamente, en la articulación equivalencial son necesarias positividades constituidas autónomamente que puedan ser igualadas en torno a un significante vacío (Laclau; Mouffe, 2015: 184). Así, para Laclau y Mouffe la autonomía es solamente un momento en la conformación de una equivalencia $y$, de hecho, la autonomía de ciertos movimientos sociales obliga muchas veces a unir alianzas y lazos para su propia supervivencia política (Ibid., 185). No obstante, para Laclau, esta complementariedad solo es asumible si entendemos, una vez más, lo social como un campo irreductible a una sutura, a su fijación final. De este principio deriva la precariedad del vínculo equivalente o hegemónico y la posibilidad de que la lógica de la autonomía colme a la primera:

No existe la equivalencia total; toda equivalencia está transitada de una precariedad constitutiva, derivada de los desniveles de lo social. Es la precariedad de toda equivalencia la que exige que sea complementada y limitada por la lógica de la autonomía (2015: 230).

Consecuentemente, la incompatibilidad entre equivalencia y autonomía queda anulada. Eso sí, ya no pueden ser consideradas como meros fundamentos de lo social, sino como lógicas sociales que actúan en distintos modos en las conformaciones de identidades políticas. Así, dos lógicas que, en principio son opuestas en su forma

${ }^{10}$ De entrada, deberíamos aclarar que aquí entendemos dos nociones de autonomía en el seno del postobrerismo: la primera refiere a la autonomía como objetivo, la liberación o las formas de cooperación social que devienen autónomas de la lógica capitalista; la segunda referiría a la autonomía como proceso, es decir, la lógica inmanentista por el que la multitud ataca los límites del imperio de manera espontánea y sin mediación o articulación entre las distintas luchas, es decir, la autonomía de cada lucha. Principalmente, nos encargaremos de esta segunda concepción de la autonomía. 
lógica, pueden revelarse como epifenoménicas en la constitución de su forma social, colaborando en dicha formación, al tiempo que contaminan la naturaleza de la otra (Laclau, 1996: 22). En ese sentido, podríamos entender la lógica autonomista como un momento en la formación de una cadena equivalencial, pero consecuentemente su crecimiento dependería de una articulación política con otras formas de autonomía. Sin articulación política el «estar en contra» de la multitud nunca puede converger. Tampoco es deducible de tal quehacer espontáneo que las luchas contra el Imperio deban coincidir en objetivos o incluso podría suceder que ciertas luchas autónomas pudieran ir las unas contra las otras (Ibid., 137). Al fin y al cabo, proponer un principio fundante en torno al cual articular un sujeto de la emancipación supone establecerlo como centro irradiador y anteponer sus «intereses» respecto a otras formas de lucha democrática. La problemática de tal suposición (que recuerda ciertamente a ciertas formas de entender la hegemonía en la tradición marxista) es que como las posiciones de sujeto nunca están explicitadas no pueden deducirse a priori los intereses de un grupo social ni, de hecho, podemos asegurar que dichos intereses vayan a converger o ir directamente en contra de otros grupos sociales. Así, por ejemplo, los intereses de la autoorganización obrera pueden atentar contra el de las mujeres, o contra el propio medio ambiente (Laclau; Mouffe, 2015: 229).

La complementariedad entre equivalencia y autonomía requiere abandonar la suposición del campo social como un terreno suturado y/o cerrado en donde las identidades ya aparezcan como fijas (Ibid., 229). Solo desde esta suposición, por la cual, este momento de cierre nunca llegaría, es que son compatibles ambas lógicas: un movimiento de autonomía requeriría de su expansión de una práctica articulatoria y la cadena equivalencial de su equivalencia con diversas formaciones, ya sean autónomas o no, y que ayudan en último término a colmar la sutura de toda equivalencia. En cierta manera, toda autonomía (si le erradicamos el mecanicismo inmanentista) requiere de una articulación más o menos precaria y abierta a su expansión. En ese sentido, desde el marco teórico posmarxista podemos encontrar la solución a esta aparente dicotomía al precio de eliminar al Spinoza negriano de la ecuación. En consecuencia, el «estar en contra» no podría ser una categoría inmanente al todo social, sino el fruto de una articulación hegemónica.

Con lo hasta ahora desarrollado, ahora podremos vislumbrar el acoplamiento del aceleracionismo de Srnicek y Williams a la lógica equivalencial de Laclau por medio de su concepción del universal, lo que indefectiblemente les alejará de cualquier concepción inmanentista de la articulación política y le acercaría a una construcción hegemónica de los agentes políticos. Primeramente, este distanciamiento respecto del postobrerismo podemos sentirlo en uno de los conceptos más acertados de la pareja británica: el concepto folk politics, con el cual Srnicek y Williams (2016: 9-13) hacen una crítica a ciertas formas de lucha (típicamente izquierdistas) basadas en la inmediatez de acciones aisladas (sin ninguna esperanza o programa real para desafiar a un sistema de naturaleza global) en vez de la apuesta por acciones estratégicas de largo alcance:

Against the abstraction and inhumanity of capitalism, folk politics aims to bring politics down to the 'human scale' by emphasizing temporal, spatial and conceptual immediacy. As its heart, folk politics is the guiding intuition 
that immediacy is always better and often more authentic, with the corollary being a deep suspicion of abstraction and mediation (Srnicek; Williams, 2016: 10).

Típicamente la tradición marxista había dado un total predominio a la estrategia por encima de la táctica. El postobrerismo, en cambio, invierte la relación propugnando la horizontalidad y la lleva al extremo al considerar tácticas aisladas sin ninguna articulación estratégica entre ellas (Laclau, 2018: 300). Si consideramos el carácter jerárquico o vertical del aceleracionismo de Srnicek y Williams, sería pues inconcebible una política de horizontalidad absoluta como la del postobrerismo, contrariamente proponen un claro dominio de la estrategia por encima de las tácticas aisladas. Además, en el proyecto de los británicos reside un impulso racionalista frente a las catástrofes de naturaleza global que hoy nos amenazan. Ante esta perspectiva, su proyecto político no se puede basar en la libre acción espontánea de los sujetos frente a un enemigo invisible, sino que propone organizar y racionalizar una producción de carácter global mediante el uso de datos y modelos informáticos. La propuesta de explorar modelos económicos, sistemas logísticos globales... es decir, que la izquierda «pierda el miedo a la abstracción y a las matemáticas» (Srnicek; Williams, 2013: 41) requiere formas de delegación y jerarquía. Esta propuesta es ciertamente similar al proyecto de la constitución de organizaciones e instituciones al margen del capital del proyecto postobrerista. Sin embargo, Srnicek y Williams conciben la autonomía desde la mediación y la articulación de intereses. En nuestra opinión no es sino evidente que Srnicek y Williams han leído las críticas que Laclau le dirigió a Negri: «sin articulación no hay política» (2016: 140) y, consecuentemente, han buscado articular la autonomía de organizaciones postcapitalistas.

Como más arriba comentamos, el concepto de universalidad vuelve a ser central para entender el tipo de articulación política de Srnicek y Williams, y se desprende necesariamente de su crítica a la particularidad y «localismo» de las folk politics para enfrentar un sistema de naturaleza global. En ese sentido, el aceleracionismo de Srnicek y Williams comparte con el posmarxismo la noción de universalidad parcial, entendida esta como una lucha hegemónica. No obstante, es concebida como un universal subversivo (lbid., 75-78). Haciéndose acopio de las críticas al concepto de universalismo que históricamente ha hecho que un particular envista un universal que subsume (de manera autoritaria) a otras particularidades, es decir, afirmando que el universal tiene un contenido propio susceptible de ser impuesto, afirman que este es un concepto de universalidad equivalente al de homogeneidad por el que necesariamente se elimina la diferencia de otras particularidades. No obstante, tal y como ya planteaban Negri y Laclau, se necesita de una unidad, y aquí es donde Srnicek y Williams plantean la necesidad de un universal que funcione como idea trascendental que nunca se satisface con un investimiento concreto, sino que siempre es extensible y en continuo conflicto:

The universal, then, is an empty placeholder that hegemonic particulars (specific demands, ideals and collectives) comes to occupy. It can operate as a subversive and emancipatory vector of change with respect to established universalisms, and it is heterogeneous and includes differences, rather than eliminating them (2016: 78). 
Srnicek y Williams afirman, en la misma línea de Laclau, que el universal no es una categoría cerrada o fija que puede investir un cierto particular anulando otros particulares, sino que un universal es un producto político, es decir, el resultado de una construcción hegemónica. El universal no puede basarse en un juicio trascendente que se sitúe por encima de una confrontación hegemónica, este debe ser necesariamente el resultado de una articulación política. Desde la perspectiva que supone afirmar que el concepto de lo universal es parcial, contingente, expansivo y sin contenido propio, y dado el desarrollo que hemos seguido entre las lógicas de autonomía y de equivalencia por el que hemos concluido que tal universal es incompatible con un proyecto autonomista, el proyecto aceleracionista de Srnicek y Williams debe ser enmarcada nítidamente en la matriz teórica del posmarxismo. Consecuentemente, el articulo alcanza su objetivo de resignificar esta propuesta como un tecnopopulismo.

\section{Conclusiones}

Habiendo analizado las perspectivas teóricas del postobrerismo y el posmarxismo, podemos concluir que el tecnopopulismo, antes que ser una derivación del postobrerismo, como los propios Negri o Bifo entendieron, se trata de una corriente filosófica de perspectiva posmarxista. La confusión de los autores italianos seguramente resida en que sus comentarios sobre el aceleracionismo de Srnicek y Williams refieren principalmente al MPA, el cual, para ser justos, no acaba del todo de enmarcar al movimiento como una forma de populismo en clave tecnológica. De ahí, y dadas las similitudes programáticas que comparte con el postobrerismo que este haya sido pensado desde tal perspectiva. Por tanto, si el aceleracionismo ha sido considerado como una «herejía marxista» dada su aparente capitalofilia, cabría pensar que simplemente se trata de un proyecto posmarxista lo que, por otra parte, para ciertos sectores del marxismo ya se trate de una herejía.

No obstante, también hemos observado como, de hecho, autonomía y equivalencia no tienen por qué ser necesariamente opuestas, o al menos no en su totalidad. Como hemos vista más arriba, de hecho, la autonomía requiere de una cierta articulación política y viceversa. A pesar de ello, como observa Laclau, aceptar la autonomía requiere la negación de su carácter de inmanencia radical y abrazar una cierta trascendencia, lo que socava necesariamente la integridad del proyecto de autonomía negriano a raíz de eliminar una universalidad a priori de los agentes sociales. En ese sentido, el postobrerismo queda integrado en el seno del tecnopopulismo en cuanto que la autonomía es redefinida en términos posmarxistas. Tal asunción, recordemos, solo es factible si eliminamos de la lógica de autonomía una noción suturada de lo social y de las identidades fijas.

Por último, queda por establecer otra posible demarcación para el postobrerismo, tal y como es concebido en el tecnopopulismo, y es que como señala Alejandro Pizzi, los puntos fuertes tanto del posmarxismo y postobrerismo residen en diferentes terrenos teóricos: mientras que el posmarxismo forma una teoría consistente en torno a la creación de identidades colectivas, pero su carácter idealista no puede explicar las transformaciones económicas y productivas en el seno del capitalismo así como 
las formas de emancipación resultantes de la misma. El postobrerismo, en cambio, carece de una teoría de la articulación y falla en el propio objetivo de explicar en qué consiste la emancipación, pero sus análisis son ciertamente certeros e incluso han sido predictivos sobre la naturaleza del capitalismo y sus cambios en el sistema de valorización (2018: 69).

Si el postobrerismo nos dota de las herramientas conceptuales para analizar las tendencias del capitalismo y buscar una transición hacia el postcapitalismo, el tecnopopulismo retomaría dichas herramientas, pero renegando que de dichas transformaciones productivas pueda extraerse o surgir una identidad política. Es decir, pese a que Srnicek y Williams compartirían con el postobrerismo una cierta lectura del Fragmento sobre las máquinas, dada también su matriz posmarxista, negarían la necesidad de la emancipación política fruto del desarrollo tecnológico-capitalista. Consecuentemente, la negación de la correlación necesaria entre estructura y superestructura dirige su lógica política hacia la articulación hegemónica laclauiana. Desde este punto de vista, sí podríamos entender al tecnopopulismo como una imbricación de ambas perspectivas, siempre y cuando estas se apliquen a ámbitos o terrenos de análisis diferenciados.

\section{Bibliografía}

ARROYO GARCÍA, Nantu; ACOSTA IGLESIAS, Lorena (2019). "Pensar el aceleracionismo, ¿con o contra Marx? El fragmento sobre las máquinas a debate en el s.XXI". Argumentos de Razón Técnica, 22, pp. 178-20.

AVANESSIAN, Armen; REIS, Mauro. (2017). "Introducción" en AVANESSIAN, Armen; REIS, Mauro. (Comps.). (2017) Aceleracionismo. Estrategias para una transición hacia el postcapitalismo. Buenos Aires: Caja Negra.

BADIOU, Alain. (2010). The communist hypothesis. Londres: Verso.

BERARDI, Franco (Bifo). (2016). Almas al trabajo. Alienación, extrañamiento, autonomía. Madrid: Enclave de libros.

- (2017) "El aceleracionismo cuestionado desde el punto de vista del cuerpo" en AVANESSIAN, Armen; REIS, Mauro. (Comps.). Aceleracionismo. Estrategias para una transición hacia el postcapitalismo. Buenos Aires: Caja Negra.

FERNÁNDEZ LIRIA, Carlos. (2016). En defensa del populismo. Madrid: Catarata. 
GÓMEZ VILLAR, Antonio. (2014). Hacia una concepción filosófica del postfordismo y la precariedad: elementos de teoría y método (post)operaísta. Tesis doctoral, Universidad Pompeu Fabra.

- (2018). Ernesto Laclau i Chantal Mouffe: Populisme i hegemonia. Barcelona: Gedisa.

GUREEV, Artem. (2018). "Beyond endless Winter: An interview with Nick Srnicek". Consultado el 27 de marzo de 2020, \&\&\& Platform en https://tripleampersand.org/beyond-endless-winter-interview-nick-srnicek/ HARDT, Michael; NEGRI, Antonio. (2002). Imperio. Barcelona: Paidos.

- (2004) Multitud. Guerra y democracia en la era del Imperio. Barcelona: Debate.

LACLAU, Ernesto. (1996). Emancipación y diferencia. Buenos Aires: Ariel.

- (2016). Debates y combates. Por un nuevo horizonte de la política. Madrid: Fondo de cultura económica.

- (2018). La razón populista. Madrid: Fondo de Cultura Económica.

LACLAU, Ernesto; MOUFFE, Chantal. (2015). Hegemonía y estrategia socialista. Hacia una radicalización de la democracia. Madrid: Siglo XXI. MARX, Karl. (1972). Elementos fundamentales para la crítica de la economía política (Grundrisse) 1857-1858, vol, 2. México: Siglo XXI, pp. 216-230.

MOUFFE, Chantal. (1999). El retorno de lo político. Madrid: Paidós.

- (2007) Prácticas artísticas y democracia agonística. Barcelona: Museu d'art contemporani de Barcelona y Universitat Autónoma de Barcelona.

- (2016). La Paradoja Democrática. Barcelona: Gedisa.

NEGRI, Antonio. (2006). La fábrica de porcelana. Una nueva gramática de la política. Barcelona: Paidós.

- (2017). "Reflexiones alrededor del Manifiesto por una Política Aceleracionista" en AVANESSIAN, Armen; REIS, Mauro (Comps.). (2017) Aceleracionismo. Estrategias para una transición hacia el postcapitalismo. Buenos Aires: Caja Negra.

NOYS, Benjamin. (2018). Velocidades Malignas. Madrid: Materia Obscura. 
SRNICEK, Nick; WILLIAMS, Alex. (2013). "Manifiesto por una Política Aceleracionista" en AVANESSIAN, Armen; REIS, Mauro (Comps.). (2017)Aceleracionismo. Estrategias para una transición hacia el postcapitalismo. Buenos Aires: Caja Negra.

- (2015). Inventing the future. Postcapitalism and a world without work. Londres: Verso.

- (2019). "¿Los robots te quitarán el trabajo?" en: Echaves, Marta; Ruido, Maria; Gómez Villar, Antonio. Working dead. Escenarios del postrabajo. Barcelona: La Virreina. Centre de la Imatge.

SRNICEK, Nick. (2018). Capitalismo de plataformas. Buenos Aires: Caja

Negra.

PIZZI, Alejandro. (2018). "Más allá de Marx: postobrerismo y posmarxismo. Una revisión de los fundamentos teóricos de la multitud y el pueblo". Arxius 38, pp. 59-72.

VILLACAÑAS BERLANGA, José Luis. (2015). Populismo. Madrid: La Huerta Grande.

WILLIAMS, Alex. (2020). Political hegemony and social complexity. Mechanisms of power after Gramsci. Londres: Palgrave Macmillan.

WOLFENDALE, Peter. (2014). "So, Accelerationism, what's all that about?". Consultado el 27 de marzo de 2020, Dialectical Insurgency en https://deontologistics.tumblr.com/post/91953882443/so-accelerationismwhats-all-that-about 